\title{
The Effect of Health Education via Mobile Apps in Promoting Asthma Health Related Quality of Life Among Asthmatic School Children in Urban Malaysia.
}

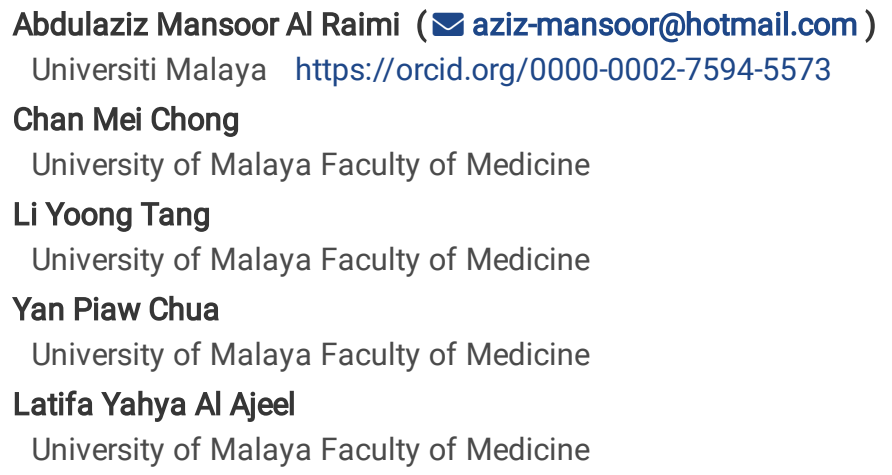

Keywords: Asthma, HRQoL, health education, mobile app, PAQOLQ

Posted Date: April 5th, 2021

DOI: https://doi.org/10.21203/rs.3.rs-340152/v1

License: (c) (1) This work is licensed under a Creative Commons Attribution 4.0 International License. Read Full License 


\section{Abstract}

Objectives: The objective of study to assess the effect of health education via mobile applications in promoting health-related quality of life among schoolchildren with asthma in urban Malaysia.

Methods: A Quasi-experimental with two-group pre- and post-intervention design was used in this study involving a total of 214 students. The students were randomly assigned into two groups (intervention group and control group) in a pre and post intervention approach. The control group received face to face education and the experimental group had health education via mobile apps.

Results: The findings showed that the total score of health related quality of life has improvement in the mean total score of health-related quality of life from pre-intervention $(5.31 \pm 1.27)$ to post-intervention $(5.66 \pm 1.28)$ for the control group, compared with the experimental group with a mean total score of $\mathrm{HRQOL}$ at pre-intervention (5.01 \pm 1.36$)$ and post-intervention (5.85 \pm 1.29$)$. A comparison between the experimental and control groups using an independent t-test showed statistically significant differences in the mean HRQoL scores of asthma between the experimental and control groups. The effect of health education via mobile applications showed statistically significant improvement pre and post intervention in HRQoL score $[F(1,288)=57.46, p=<0.01]$.

Conclusion: The use of mobile technology in health education improved HRQoL as compared of traditional method of face-to-face lecture or handbooks among school children with asthma. Thus, educational module using mobile apps improves HRQoL.

Trial registration: This study was registered under the Medical Research Committee, University Malaya Medical Centre, Malaysia under Trial MRECID. NO: 2016112-4501, Also, this study is registered with the Australian New Zealand Clinical Trials Registry (ANZCTR) under Trial ID: ACTRN12614300582550

\section{Introduction}

Asthma is a chronic inflammatory disease of the airways with hyperresponsiveness of bronchial to a difference of stimuli which lead to obstruction of airflow that can be reversible by self or by treatment (1), it is one of the most chronic illnesses prevalent among adolescents in industrialized societies (2).

The global prevalence of asthma varies from one country to another and ranged between $5 \%$ to $20 \%$ or even more (3). Among the asthmatic patients 3 to $10 \%$ suffer from severe asthma. Moreover, $10 \%$ to $25 \%$ of the asthmatic patient in a specialty clinic have severe asthma (4). Asthma is gradually becoming a burden among children in Malaysia and it has been categorized as one of the most influencing factors affecting the quality of life of children and their parents (5).

Poorly managed effects of asthma can affect the children's health-related quality of life, studies have also shown that low health-related quality of life increases future emergency room visits relating to asthma, which means inadequate control of asthma (6). Asthma can affect the health-related quality of life because the disease or treatment process could change a person's physical, psychological and social functions (7), since it does not only affect the asthmatic children but also their parents (8).

Education is the main key to improving patient knowledge, skill, and compliance, especially for patients with poor knowledge and compliance (9) So, improving the knowledge of schoolchildren about asthma relates to reducing distress and severity and thus improving the healthrelated quality of life, and this can provide nursing staff with guidance in developing nursing instruction to improve the active quality of life in children (10).

There are challenges to the introduction of face-to-face approaches in asthma health education programs, barriers include transportation issues, healthcare environment limitations such as non-adherence training, organizational obstacles like hospital hours, locations, and time limitations (11). Health education via mobile app can potentially mitigate the adverse effects by helping users detect and treat early symptoms before progressing to a poorly controlled state. (12). Mobile health apps can promote prevention and can be a highly useful method for providing successful health services to encourage supportive family support as early teens develop asthma and learn selfmanagement habits (13).

Smartphones are used by about $50 \%$ of adolescents aged $12-17$ years old and $75 \%$ of adults aged $30-49$ years old, so there is a strong need for an intervention in mHealth directed at supportive family assistance as early adolescents with chronic asthma shift to take more responsibility for their asthma treatment (13).

Unfortunately, the literature in the usage of smartphone technology in patient care is lacking. Most healthcare app users focus on monitoring their condition rather than improving knowledge or how to deal effectively with the disease (14). In particular, few studies are available 
evaluating the effectiveness of smartphone usage in children's health education and how health education can improve the patient's HRQoL (9).

The present study is part of research project under the title: Developing Children Asthma Program (CAP) in promoting health outcomes among school children in Malaysia. The aim of this study is to assess the effect of health education via mobile apps in promoting asthma healthrelated quality of life among asthmatic school children in urban Malaysia.

\section{Methods}

\section{Design}

This is a quantitative study, in the form of a quasi-experimental, non-equivalent pre-test and post-test with control group design. According to (15). A quasi-experimental is a research design used to evaluate interventions that do not involve randomization (16). The researcher chose this design because of the inability to manipulate or control the environment and randomized subjects. Randomization is difficult in educational studies, and since this study took place in a group environment which included schoolchildren in classrooms, the sample could not be solely monitored by the researcher (17). This study design would also include research to assess the differences between the pre-test results of the study and control groups, variations between pre-test and post-test results, and variations between the post-test outcome of the study and control groups that are compatible with the particular objectives of this current study.

As shown in Figure 1, the participants were divided into two groups according to selected schools randomly. The schoolchildren in the experimental group were from different schools than those in the control group. In this study, the control group used only traditional methods (face-to-face) and the experimental group received education using a smartphone application. In addition, there employed 'controlled before and after', a control population with similar characteristics to the study population and are expected to have similar changes that occur to the study population (18). The outcome measures were assessed after 3 months, post-intervention, for both groups We chose randomly 6 schools located in Petaling Jaya city within the state of Selangor, Malaysia, then we randomly assigned the schools into 2 groups, 3 schools chose to consider as experimental group and 3 schools consider as control group, then we recruited schools children whose met the inclusion criteria. According to Brydges (19), the study sample sizes required for group differences research to achieve estimated medium effects size levels of $80 \%$ statistical power by using a prior power analysis with $a=.05$ (two-tailed), were 107 subjects are allocated to each group, so a total of 214 schoolchildren involved for the entire study. The inclusion criteria were students having asthma diagnosis, students showing asthma symptoms in the last 12 months, have smartphone and students who speak either English or Malay. The exclusion criteria were students who do not have significant comorbidity disease and students who refuse to participate in the study.

\section{The Research Phases}

This research was conducted in four phases. The first phase was constructing the health education program about bronchial asthma "Asthma Care Program ${ }^{\circledR}$ ” and mobile application developing “MemahamiAsma ${ }^{\circledR}$ " that began with an extensive literature review. The second phase was conducting a quasi-experimental study which first used a survey to identify eligible participants according to the inclusion criteria by a pre-intervention assessment. The third phase the control groups attended the session face to face of health education regarding asthma, and the experimental group they received firstly face to face classroom learning for 1 hour, then after the face to face lecture, the mobile appbased learning was administering to the students for 3 months. The last phase was the follow-up three months after the health education intervention for the control and experimental groups using a self-administered questionnaire, similar to that at pre-health education intervention, to assess the schoolchildren' HRQoL.

\section{Study Instruments:}

\section{Demographical Data}

This part was developed by the researcher based on previous studies $(3,20-23)$. This data consists of the schoolchildren's general information, their demographical status, gender, age, race, and family history of asthma. The aim of this questionnaire is to evaluate the correlation between demographic factors and HRQoL level among asthmatic schoolchildren.

\section{Health-Related Quality of life of Questionnaire.}

The questionnaire used to measure the health-related quality of life of the students was adopted from the Pediatric Asthma Quality of Life Questionnaire (PAQOLQ) which was designed and validated by Juniper et al. (1996). This instrument contains 23 questions in three domains 
(symptoms, activity limitations and emotional function). Children were asked to recall their experiences during the previous week and to respond to each question on a 7-point scale.

\section{The tools of health education intervention}

\section{Educational pamphlet "Asthma Care Program®"}

Asthma Care Program is the children asthma hand pamphlet developed by the researcher in both language English and Bahasa Malaysia based on the review of the literature and evaluation by a panel of experts. This tool designed to be colorful, entertaining, educational, and developmentally appropriate as well as diverse in regard to gender, race, and culture. The content of the workbook includes anatomy and physiology of the lungs, management, and prevention of disease. This hand workbook will distribute to the control group (Figure 2)

\section{Mobile App “MemahamiAsma®”}

Mobile asthma app called: MemahamiAsma ${ }^{\circledR}$ was developed by android developer specialist incorporation with research team in both language: English and Bahasa Malaysia to support children with asthma for their daily care. The mobile app is electronic alternative for hand workbook tool that contain all data need for asthma and can support school children about asthma.

\section{App design process}

The design process of MemahamiAsma ${ }^{\circledR}$ is based on the goal-directed design (GDD) (24) and Health Literacy Online's six main strategies (25). To simplify the process of the design, modifications were made to both aforementioned methods by dividing the design process into four stages covering the two phases of development and deployment. Figure 3 depicts the proposed design process of MemahamiAsm

\section{Usability manual}

Understanding Asthma or MemahamiAsma ${ }^{\circledR}$ is a simple-to-use and straight-to-the-point android application for high school students from Malaysia. The application is developed in both English and Malay as shown in Figure 4.

In the first page that the user will see login page. They have to enter their login ID and password. The user then has to choose their preferred language, either English or Malay. After choosing their language, the user will be greeted by this page. The tabbed page is populated with INFO, tabs on asthma information as well as tabs on frequently asked questions (FAQ). The last page is contacts page which to help students understand more, if advance knowledge and information regarding asthma or asthma research or any related events or activities is needed, we have provided them with the contacts to societies related to asthma which are the Malaysia Thoracic Society (MTS) and the Malaysia Society of Allergy and Immunology (MSAI),

\section{Data Collection:}

The data collection was carried out from April 2015 until September 2016 in the selected schools. We collected data for both groups separately to avoid contamination of data. The sample were randomly divided two groups: Experimental group and Control group. The control group will have met for session delivered one time take one session of face to face lecture about the asthma and they will take hand workbook will be designed to be colorful, entertaining, educational, and developmentally appropriate as well as diverse in regard to gender, race, and culture. The content of the workbook includes anatomy and physiology of the lungs, management, and prevention of disease. The experimental group they received firstly face to face classroom learning for 1 hour. Flowing the face to face learning mobile app-based learning was administer for 2 months which was electronic alternative for hand workbook tool, the frequency and duration of use of the mobile application it will be flexible and according to user prefer to use it for 3 months.

\section{Data analysis}

Data were analyzed using Social Package Statistical Software (SPSS) version 22. Descriptive and inferential statistics were used to summarize the demographics of the school children and their level of HRQoL. Quantitative data included the calculation of mean and standard deviation. The associations between categories were determined using the Chi-squared test and the pretest and posttest to analyses the difference mean was used Split-plot ANOVA. The statistically significant is fixed at $p<0.05$. 


\section{Results \\ Profile of the sample}

A total of 214 school children participated in the study with 107 of the students in the control group and 107 in the intervention group. The data from the table show that female students made up more than half of all students in both control and experimental groups, $(\mathrm{n}=55$, $51.4 \%)$ and $(n=63,58.9 \%)$ respectively. Also, there were more students aged $15-16$ years old than $13-14$ years old in the control group ( $n=59$, $55.1 \%)$ and the experimental group ( $n=62,57.9 \%)$. Regarding ethnicity, around two-third of the students are Malay, $(n=73,68.2 \%)$ in the control group and $(n=72,67.3 \%)$ in the experimental group; Indian, $(n=25,23.4 \%)$ in the control group and $(n=18,16.8 \%)$ in the experimental group; and Chinese, $(n=9,8.2 \%)$ in the control group and $(n=17,15.9 \%)$ in the experimental group.

In addition, the results showed the age of more than half of the students in the control group ( $n=60,56 \%)$ and the experimental group ( $n=55$, $51 \%$ ) had been first diagnosed with asthma between $0-6$ years old, while around half of them from both the control and experimental group, $(n=45,42 \%)$ and $(n=48,45 \%)$ respectively, were diagnosed with asthma in a hospital. (Table 1$)$.

\section{Relationship Between Demographic Characteristics and HRQoL at Pre- Intervention for the Control and Experimental Group}

The result in Table 2 shows that the health-related quality of life level of 'No Impairment' was highest in the control group whereas 'Moderate Impairment' was highest in the experimental group. In the control group, 'No Impairment' was highest for the following factors: 15 -16 years old $(n=34,58.6 \%)$, Malay ethnic ( $n=43,58.9 \%)$, and male students $(n=35,67.2 \%)$. Meanwhile, in the experimental group, 'Moderate Impairment' was highest for the following factors: $14-15$ years old $(n=29,48.8 \%)$, Malay ethnic $(n=45,62.5 \%)$, and female students ( $n=39,61.9 \%)$.

However, there was no statistically significant difference $(p<0.05)$ in the health-related quality of life level throughout, so univariate logistic model analysis was not conducted in this situation. Thus, the demographic variables do not influence the dependent variables, HRQoL.

\section{HRQoL level and Sub-scales domains}

As can be seen from Table 3, shows the mean total HRQoL score in the control group, there was a slight increase in the mean total healthrelated quality of life score from pre-intervention (5.31 \pm 1.27$)$ to post-intervention (5.66 \pm 1.28$)$. Meanwhile, the experimental group experienced a significant increase in the mean total health-related quality of life score from pre-intervention (5.01 \pm 1.36$)$ to post-intervention (5.85 \pm 1.29 ). Regarding the HRQoL domains: in the control group, the highest score for the health-related quality of life domain of schoolchildren is symptoms functioning at pre-intervention (4.99 \pm 1.39$)$ and post-intervention (5.92 \pm 1.09$)$, whereas the lowest score was for activity limitation at pre-intervention $(5.19 \pm 1.33)$ and emotional functioning at post-intervention (5.48 \pm 1.39$)$. Furthermore, in the experimental group, the highest score for the health-related quality of life domain of schoolchildren is symptoms functioning at pre- and post-intervention, (5.13 \pm 1.53$)$ and $(6.09 \pm 1.26)$ respectively, whereas the lowest score was emotional functioning at pre- and post-intervention, (4.9 \pm 1.27$)$ and $(5.57 \pm 1.41)$ respectively.

A comparison between the experimental and control groups using an independent t-test showed statistically significant differences in the mean health-related quality of life scores between the experimental and control groups

\section{The effectiveness of health education via mobile application}

This research question was answered using inferential statistics. Generalized Linear Model (GLM), Split-Plot ANOVA (SPANOVA) was used to examine the significant difference in the mean score of HEQoL improvement among the schoolchildren with asthma between the experimental and control group.

Table 4 presents the summary of SPANOVA results of within-subjects effects (pre- and post-intervention score of HRQoL level) and betweensubject effects (the experimental and control groups). The null hypothesis is rejected, and the effect of the mobile app is significantly effective in improving HRQoL level of the students. The profile plot in Figure 5 clearly indicates that the HRQoL level for the experimental group increased from pre-test to post-test.

\section{Discussion}

The present study reveals that poor asthma control will affect the daily life of asthmatic schoolchildren and their adaptation to the illness in several aspects of life such as the physical, emotional, and social. The complication of asthma may affect the daily normal function of 
school-age children in the aspects of the physical and psychological. They would also have a high risk of school absenteeism (26). In the USA, the National Interview Survey mentioned that children with asthma have 3 times more school absentees and have more risk of learning disability compared with normal children (27).

In this study, the emotional sub-scale contributed the most to the schoolchildren's HRQoL impairment in both groups, and this is consistent with previous studies which revealed that adolescents with persistent asthma had common emotional symptoms related to asthma due to increased asthma morbidity, healthcare use, and school absenteeism. On the other hand, it would mean that adolescents with high morbidity from asthma have a high risk of poorer HRQoL. Therefore, emotional HRQoL should be included in the assessment of adolescents with asthma (28). Another study was done in Saudi Arabia to assess the influence of attitude on asthma severity and health-related quality of life among asthmatic children. Their levels of health-related quality of life also show a higher score in the emotional domain compared to the physical (29).

Furthermore, in the USA, there reported slightly poorer emotional processing in Hispanic children in comparison to the non-Hispanic White and African American children. The emotional sub-scale explored how often children feel upset, anxious, worried, or distressed because of their asthma and how often they are scared by an asthma attack (30). Poor asthma control among children is a manifested public health problem. It causes respiratory health problems, limits physical activity, and leads to missed school days and also parental work absenteeism (31). different studies found that physical functioning and vitality are the typical measurements most impaired by asthma, and the explanation for this contradicts our study conducted among schoolchildren with mild asthma, as these other studies are performed among those with moderate to extreme illness, where the study population had weak physical functioning (32).

On the other hand, the present study reveals the effect of a mobile app in promoting health-related quality of life among asthmatic schoolchildren, the result of this study is closely similar to the previous systemic review which aimed to assess the effect of a mobile apps to support adult patients with asthma; the result demonstrated that both patients with asthma and healthcare providers have improved healthrelated quality of life (33). Another study in the USA that assessed a mobile technology-based educational program on schoolchildren to improve asthma self-management and outcomes found that parents of the schoolchildren demonstrated significant improvements in their asthma caregiver-related quality of life (34).

It is therefore concluded that the use of mobile technology in health education has good impact in improving HRQoL of school children with asthma as compared to other traditional methods like face to face lecture or hand books. This finding agrees with findings of other researches which revealed that the mobile health (mHealth) initiatives have impact in improving of chronic disease conditions(35). In another systemic review conducted by Majeed-Ariss, Baildam (36) it was explained that mobile apps have good benefits to adolescent since the mobile technologies and featuring software apps are now widely used by this age group either for social networking or for gaming purposes. Hence the apps could be used for health care educational purposes or for healthcare supports.

As recommended in the literature review by (37), there is a need to assess efficacy and cost-effectiveness for using information technology to improve asthma treatment and knowledge, which must be reinforced by randomized trials. The outcomes of such studies are urgently needed. The simplicity with which these strategies integrate into our everyday lives and the meaning of continuous chronic care indicates that these imaginative and innovative approaches may be a beneficial addition to successful clinical practice.

\section{Practice Implications}

Various studies have emphasized the important of active health education to increase level of HRQoL among asthmatic patient. This study will equip the new way in health education for school children with asthma, as well as the measures that need to be taken to control the asthma. Consequently, the school children may develop the right attitude in handling asthma management care which may as well lead them to positively to their HRQoL.

\section{Limitations and Recommendations}

The first limitation identified in this study is due to its quasi-experimental design. There was the absence of randomization, due to the absence of randomization, there is likely the presence of selection bias. There realized that self-reported questionnaires could lead to introducing bias to the results of the study, as it might not describe the true condition of the participants; they might rate higher or lower than the true condition. Other limitations include the probability of some participants failing to install the app, reason undetermined (might have occurred during 
registration). Also, we do not know if any of the schoolchildren in the control group had somehow accessed or downloaded the app. Similarly, we did not account for the use of other asthma mobile health software by the participants.

In this study, data on the patients' perception of illness, self-motivation, and approaches on self-management were not collected. Therefore, it is recommended for future research to investigate further regarding symptoms experienced by patients through the methodology of gathering information on illness perceptions, self-motivation, self-efficacy, and self-management strategies. Data retrieved can be integrated into psycho-educational programmes to promote behaviour change, hence improving the patients' self-management skills.

\section{Conclusion}

In this quasi-experimental research, there concluded the finding - the use of mobile technology in health education improves HRQoL levels of schoolchildren with asthma, compared with other traditional methods like face-to-face lecture or handbooks. So, we concluded the using of mobile technology in health education has good impact in improving the school children with asthma HRQoL as compared to other traditional methods like face to face lecture or hand books.

\section{Declarations}

\section{Acknowledgement}

We would like to thank the University of Malaya Research Grant for their funding and sponsors of this study under scheme Postgraduate Research Grant (PPP) No. PG196-2015A. We would also like to express Also I am thankful to Dr. Mohammed Al-Mekhlafi and Dr. Mohammed A. Al-Sharafi for their kind help and advices.

\section{Author Declarations:}

- Funding: This study was funded under the Institute of Research Management and Services (IPPP), University Malaya PG196-2015A.

- Conflicts of interest/Competing interests: The authors declare that they have no conflicts of interest.

- Availability of data and material: 'N/A'

- Code availability: 'N/A'

- Authors' contributions: 'N/A'

- Ethics approval: Permission was granted by the Ministry of Education, the Ministry of Health, and the respective schools and principals. This study was registered under the Medical Research Committee, University Malaya Medical Centre, MRECID. NO: 2016112-4501, Also, this study is registered with the Australian New Zealand Clinical Trials Registry (ANZCTR) under Trial ID: ACTRN12614300582550

- Consent to participate: Written consent was obtained from the participants and they were informed that refusal to participate would not result in negative consequences.

- Consent for publication: 'N/A'

\section{References}

1. Fajt ML, Wenzel SE. Development of New Therapies for Severe Asthma. Allergy Asthma Immunol Res. 2017;9(1):3-14.

2. Alquran A, Lambert KA, Farouque A, Holland A, Davies J, Lampugnani ER, et al. Smartphone Applications for Encouraging Asthma SelfManagement in Adolescents: A Systematic Review. Int J Environ Res Public Health. 2018;15(11):2403.

3. Shimwela M, Mwita J, Mwandri M, Rwegerera G, Mashalla Y, Mugusi F. Asthma prevalence, knowledge, and perceptions among secondary school pupils in rural and urban coastal districts in Tanzania. BMC Public Health. 2014;14(1):387.

4. Kim S-H, Moon JY, Lee JH, Ban G-Y, Kim S, Kim M-A, et al. Perceptions of Severe Asthma and Asthma-COPD Overlap Syndrome Among Specialists: A Questionnaire Survey. Allergy Asthma Immunol Res. 2018;10(3):225-35.

5. Fadzil A, Norzila MZ. Parental asthma knowledge. Med J Malaysia. 2002;57(4):474-81.

6. Ahmad N, Ismail A, Sulong S, Rahman RA. Determinant for Quality of Life among Childhood Asthma in Malaysia: A Cross Sectional Study. International Medical Journal. 2017;24(2):195-9.

7. Patrick DL, Bergner M. Measurement of health status in the 1990s. Annu Rev Public Health. 1990;11:165-83.

8. Stelmach I, Podlecka D, Smejda K, Majak P, Jerzyńska J, Stelmach R, et al. Pediatric Asthma Caregiver's Quality of Life Questionnaire is a useful tool for monitoring asthma in children. Qual Life Res. 2012;21(9):1639-42. 
9. Choi JY, Cho Chung HI. Effect of an individualised education programme on asthma control, inhaler use skill, asthma knowledge and health-related quality of life among poorly compliant Korean adult patients with asthma. Journal of clinical nursing. 2011;20(1-2):11926.

10. Yang BH, Chen YC, Chiang BL, Chang YC. Effects of nursing instruction on asthma knowledge and quality of life in schoolchildren with asthma. The journal of nursing research: JNR. 2005;13(3):174-83.

11. Ramsey RR, Plevinsky JM, Kollin SR, Gibler RC, Guilbert TW, Hommel KA. Systematic Review of Digital Interventions for Pediatric Asthma Management. The Journal of Allergy Clinical Immunology: In Practice. 2020;8(4):1284-93.

12. Rhee H, Belyea MJ, Sterling M, Bocko MF. Evaluating the Validity of an Automated Device for Asthma Monitoring for Adolescents: Correlational Design. J Med Internet Res. 2015;17(10):e234-e.

13. Fedele DA, McConville A, Graham Thomas J, McQuaid EL, Janicke DM, Turner EM, et al. Applying Interactive Mobile health to Asthma Care in Teens (AIM2ACT): Development and design of a randomized controlled trial. Contemporary Clinical Trials. 2018;64:230-7.

14. Haze KA, Lynaugh J. Building patient relationships: a smartphone application supporting communication between teenagers with asthma and the RN care coordinator. Computers, informatics, nursing: CIN. 2013;31(6):266-71; quiz 72 - 3.

15. Houser J. Nursing research: Reading, using and creating evidence: Jones \& Bartlett Learning; 2016.

16. Harris AD, McGregor JC, Perencevich EN, Furuno JP, Zhu J, Peterson DE, et al. The use and interpretation of quasi-experimental studies in medical informatics. Journal Of The American Medical Informatics Association: JAMIA. 2006;13(1):16-23.

17. Stone R, Cooper S, Cant R. The value of peer learning in undergraduate nursing education: A systematic review. ISRN nursing. $2013 ; 2013$.

18. Grimshaw J, Campbell M, Eccles M, Steen N. Experimental and quasi-experimental designs for evaluating guideline implementation strategies. Fam Pract. 2000;17(Suppl 1):11-6.

19. Brydges CR. Effect Size Guidelines, Sample Size Calculations, and Statistical Power in Gerontology. Innovation in Aging. 2019;3(4).

20. Solis Soto M, Patino A, Nowak D, Radon K. Prevalence of asthma, rhinitis and eczema symptoms in rural and urban school-aged children from Oropeza Province - Bolivia: a cross-sectional study. BMC Pulm Med. 2014;14(1):40.

21. Mehravar F, Rafiee S, Bazrafshan B, Khodadost M. Prevalence of asthma symptoms in Golestan schoolchildren aged 6-7 and 13-14 years in Northeast Iran. Frontiers of Medicine. 2016;10(3):345-50.

22. Narayana PP, Prasanna MP, Narahari S, Guruprasad AM. Prevalence of asthma in school children in rural India. Annals of thoracic medicine. 2010;5(2):118.

23. Quah BS, Razak AR, Hassan MH. Prevalence of asthma, rhinitis and eczema among schoolchildren in Kelantan, Malaysia. Acta paediatrica Japonica; Overseas edition. 1997;39(3):329 - 35.

24. Duan H, Wang Z, Ji Y, Ma L, Liu F, Chi M, et al. Using goal-directed design to create a mobile health app to improve patient compliance with hypertension self-management: development and deployment. JMIR mHealth uHealth. 2020;8(2):e14466.

25. Hou S-I. Health literacy online: A guide to writing and designing easy-to-use health web sites. Los Angeles: Sage Publications Sage CA; 2012.

26. Anwar H, Hassan N, Jaffer N, Al-Sadri E. Asthma Knowledge among Asthmatic School Students. Oman Medical Journal. 2008;23(2):905.

27. Cicutto L, Gleason M, Szefler SJ. Establishing school-centered asthma programs. Journal of Allergy Clinical Immunology. 2014;134(6):1223-30.

28. Cerdan NS, Alpert PT, Moonie S, Cyrkiel D, Rue S. Asthma severity in children and the quality of life of their parents. Appl Nurs Res. 2012;25(3):131-7.

29. Alsamghan AS, Awadalla NJ, Mohamad YA, Hassan AM. Influence of altitude on pediatric asthma severity and quality of life in southwestern Saudi Arabia. Egyptian Journal of Chest Diseases Tuberculosis. 2016;65(3):555-61.

30. Horner SD, Brown SA, Walker VG. Is rural school-aged children's quality of life affected by their responses to asthma? J Pediatr Nurs. 2012;27(5):491-9.

31. Gerald LB, Gerald JK, Zhang B, McClure LA, Bailey WC, Harrington KF. Can a school-based hand hygiene program reduce asthma exacerbations among elementary school children? Journal of Allergy Clinical Immunology. 2012;130(6):1317-24.

32. Sararaks S, Rugayah B, Azman A, Karuthan C, Low L. Quality of Life-How Do Malaysian Asthmatics Fare? Med J Malaysia. 2001;56(3):350-8.

33. Hui CY, Walton R, McKinstry B, Jackson T, Parker R, Pinnock H. The use of mobile applications to support self-management for people with asthma: a systematic review of controlled studies to identify features associated with clinical effectiveness and adherence. $\mathrm{J}$ Am Med Inform Assoc. 2017;24(3):619-32. 
34. Warren CM, Dyer A, Blumenstock J, Gupta RS. Leveraging Mobile Technology in a School-Based Participatory Asthma Intervention: Findings From the Student Media-Based Asthma Research Team (SMART) Study. American Journal of Health Education. 2016;47(2):5970.

35. Everhart RS, Heron KE, Leibach GG, Miadich SA. Developing a Mobile Health Intervention for Low-Income, Urban Caregivers of Children with Asthma: A Pilot Study. Pediatric Allergy, Immunology \& Pulmonology. 2017;30(4):252-6.

36. Majeed-Ariss R, Baildam E, Campbell M, Chieng A, Fallon D, Hall A, et al. Apps and Adolescents: A Systematic Review of Adolescents' Use of Mobile Phone and Tablet Apps That Support Personal Management of Their Chronic or Long-Term Physical Conditions. J Med Internet Res. 2015;17(12):e287.

37. Mosnaim GS, Powell LH, Rathkopf M. A Review of Published Studies Using Interactive Internet Tools or Mobile Devices to Improve Asthma Knowledge or Health Outcomes. Pediatric Allergy Immunology Pulmonology. 2012;25(2):55-63.

\section{Tables}

Table 1: Baseline socio-demographic characteristics $(\mathrm{N}=290)$

\begin{tabular}{|c|c|c|c|c|}
\hline Variables & Control Group & Experimental Group & $x^{2}$ & $P$ \\
\hline $\mathrm{n}(\%)$ & $\mathrm{n}(\%)$ & & & \\
\hline Gender & & & .086 & .769 \\
\hline Male & $52(48.6)$ & $44(41.1)$ & & \\
\hline Female & $55(51.4)$ & $63(58.9)$ & & \\
\hline \multicolumn{5}{|l|}{ Age } \\
\hline $13-14$ & $48(44.9)$ & $45(42.1)$ & 1.476 & .478 \\
\hline $15-16$ & $59(55.1)$ & $62(57.9)$ & & \\
\hline Ethnic & & & 6.682 & .083 \\
\hline Malay & $73(68.2)$ & $72(67.3)$ & & \\
\hline Indian & $25(23.4)$ & $18(16.8)$ & & \\
\hline Chinese & $9(8.2)$ & $17(15.9)$ & & \\
\hline Age of asthma diagnosed. & & & 5.454 & 0.708 \\
\hline $0-6$ years old & $60(56)$ & $55(51)$ & & \\
\hline $6-13$ years old & $47(44)$ & $52(49)$ & & \\
\hline Where was your asthma first diagnosed? & & & 264.981 & $<0.001$ \\
\hline Hospital & $45(42)$ & $48(45)$ & & \\
\hline Clinics & $36(33)$ & $48(45)$ & & \\
\hline Nonspecific & $27(25)$ & $11(10)$ & & \\
\hline Total & $107(100)$ & $107(100)$ & & \\
\hline
\end{tabular}

Table 2: Relationship between demographics characteristics and HRQoL levels pre- intervention ( $n=107)$ 


\begin{tabular}{|c|c|c|c|c|c|c|c|c|c|c|}
\hline \multirow[t]{4}{*}{ Factors } & \multicolumn{4}{|c|}{ Control Group } & \multirow{4}{*}{$\begin{array}{l}\text { Chi- } \\
\text { square } \\
x^{2} \\
P\end{array}$} & \multicolumn{4}{|c|}{ Experimental group n (\%) } & \multirow{4}{*}{$\begin{array}{l}\text { Chi- } \\
\text { square } \\
x^{2} \\
P\end{array}$} \\
\hline & \multirow[t]{3}{*}{$\mathrm{N}=107$} & \multirow{2}{*}{\multicolumn{3}{|c|}{$\begin{array}{l}\text { HRQoL level } \\
\text { n (\%) }\end{array}$}} & & \multirow[t]{3}{*}{$\mathrm{N}=107$} & \multirow{2}{*}{\multicolumn{3}{|c|}{$\begin{array}{l}\text { HRQoL level } \\
\text { n (\%) }\end{array}$}} & \\
\hline & & & & & & & & & & \\
\hline & & $\begin{array}{l}\text { No } \\
\text { impairment }\end{array}$ & $\begin{array}{l}\text { Moderate } \\
\text { impairment }\end{array}$ & $\begin{array}{l}\text { Severe } \\
\text { impairment }\end{array}$ & & & $\begin{array}{l}\text { No } \\
\text { impairment }\end{array}$ & $\begin{array}{l}\text { Moderate } \\
\text { impairment }\end{array}$ & $\begin{array}{l}\text { Severe } \\
\text { impairment }\end{array}$ & \\
\hline Gender & & & & & & & & & & .179 \\
\hline Male & 52 & $35(67.3)$ & $16(30.8)$ & $1(1.9)$ & .177 & 44 & 18(40.9) & $26(59.1)$ & $0(0.0)$ & \\
\hline Female & 55 & $30(54.5)$ & $23(41.9)$ & $2(3.6)$ & & 63 & $20(31.7)$ & $39(61.9)$ & $4(6.3)$ & \\
\hline Age & & & & & & & & & & .597 \\
\hline $13-14$ & 48 & $31(64.6)$ & 15(31.3) & $2(4.2)$ & .376 & 45 & $18(40.0)$ & $26(57.8)$ & $1(2.2)$ & \\
\hline $15-16$ & 59 & $34(58.6)$ & $24(39.7)$ & $1(1.7)$ & & 62 & $20(32.3)$ & $39(62.9)$ & $3(4.8)$ & \\
\hline Ethnic & & & & & & & & & & .717 \\
\hline Malay & 73 & $43(58.9)$ & $27(37)$ & $3(4.1)$ & .685 & 72 & 23(31.9) & $46(63.9)$ & $3(4.2)$ & \\
\hline Indian & 25 & $17(68)$ & $8(32)$ & $0(0.0)$ & & 18 & $8(44.4)$ & $10(55.6)$ & $0(0.0)$ & \\
\hline Chinese & 9 & $5(55.6)$ & $4(44.4)$ & $0(0.0)$ & & 17 & $7(41.2)$ & $9(52.9)$ & 1(5.9) & \\
\hline
\end{tabular}

*Significant level at $p<0.05$

Table 3: Descriptive statistics of the HRQoL domains by experimental and control groups $(n=214)$

\begin{tabular}{|c|c|c|c|c|c|c|c|c|c|}
\hline \multirow[t]{3}{*}{ Domains } & \multicolumn{4}{|c|}{$\begin{array}{l}\text { Control group } \\
(\mathrm{N}=107)\end{array}$} & \multicolumn{4}{|c|}{$\begin{array}{l}\text { Experimental group } \\
(\mathrm{N}=107)\end{array}$} & \multirow{3}{*}{$\begin{array}{l}\text { Between } \\
\text { groups } \\
\text { (Exp. vs. } \\
\text { Con.) } \\
p\end{array}$} \\
\hline & \multicolumn{2}{|c|}{$\begin{array}{l}\text { The mean total of HRQoL } \\
M \pm S D\end{array}$} & $\begin{array}{l}\text { Diff. } \\
\text { (Post- } \\
\text { Pre.) }\end{array}$ & $\begin{array}{l}\text { Within } \\
\text { group }\end{array}$ & \multicolumn{2}{|c|}{$\begin{array}{l}\text { The mean total of HRQoL } \\
M \pm S D\end{array}$} & $\begin{array}{l}\text { Diff. } \\
\text { (Post- } \\
\text { Pre.) }\end{array}$ & $\begin{array}{l}\text { Within } \\
\text { group }\end{array}$ & \\
\hline & $\begin{array}{l}\text { Pre-health } \\
\text { education }\end{array}$ & $\begin{array}{l}\text { Post-health } \\
\text { education }\end{array}$ & $M \pm S D$ & $\begin{array}{l}\text { Paired } \\
\text { t test, } \\
p\end{array}$ & $\begin{array}{l}\text { Pre-health } \\
\text { education }\end{array}$ & $\begin{array}{l}\text { Post-health } \\
\text { education }\end{array}$ & $M \pm S D$ & $\begin{array}{l}\text { Paired } \\
\text { t test, } \\
p\end{array}$ & \\
\hline $\begin{array}{l}\text { Overall } \\
\text { mean }\end{array}$ & $5.31(1.27)$ & $5.66(1.28)$ & $\begin{array}{l}0.35 \\
(1.25)\end{array}$ & $<0.001$ & $5.01(1.36)$ & $5.85(1.29)$ & $\begin{array}{l}0.84 \\
(1.41)\end{array}$ & $<0.001$ & $<0.001$ \\
\hline $\begin{array}{l}\text { Activity } \\
\text { limitation }\end{array}$ & 5.19 (1.33) & $5.57(1.43)$ & $\begin{array}{l}0.39 \\
(1.25)\end{array}$ & 0.03 & $5.03(1.56)$ & $5.81(1.48)$ & $\begin{array}{l}0.78 \\
(1.67)\end{array}$ & $<0.001$ & $<0.001$ \\
\hline Emotional & 4.99 (1.39) & $5.48(1.39)$ & $\begin{array}{l}0.49 \\
(1.60)\end{array}$ & $<0.001$ & 4.9 (1.27) & $5.57(1.41)$ & $\begin{array}{l}0.67 \\
(1.51)\end{array}$ & $<0.001$ & $<0.001$ \\
\hline Symptoms & 5.44 (1.37) & $5.92(1.09)$ & $\begin{array}{l}0.49 \\
(1.36)\end{array}$ & $<0.001$ & $5.13(1.53)$ & $6.09(1.26)$ & $\begin{array}{l}0.97 \\
(1.51)\end{array}$ & $<0.001$ & $<0.001$ \\
\hline
\end{tabular}

Note:

Within group - pre and post comparison within experimental and control

Between group -comparison between experimental and control

Table 4: SPANOVA results for effectiveness of health education vis mobile app 


\begin{tabular}{|c|c|c|c|c|c|}
\hline & Sum of Squares & df & Mean Square & $\mathbf{F}$ & $\mathbf{p}$ \\
\hline \multicolumn{6}{|c|}{ Within-subjects } \\
\hline Test & 51.27 & 1 & 51.27 & 57.46 & $<0.01$ \\
\hline Test* Group & 8.69 & 1 & 8.69 & 9.74 & $<0.01$ \\
\hline Error (Test) & 257.01 & 288 & 257.01 & & \\
\hline \multicolumn{6}{|c|}{ Between-subjects } \\
\hline Group & .446 & 1 & .446 & .178 & .673 \\
\hline Error & 720.797 & 288 & 2.503 & & \\
\hline
\end{tabular}

Figures

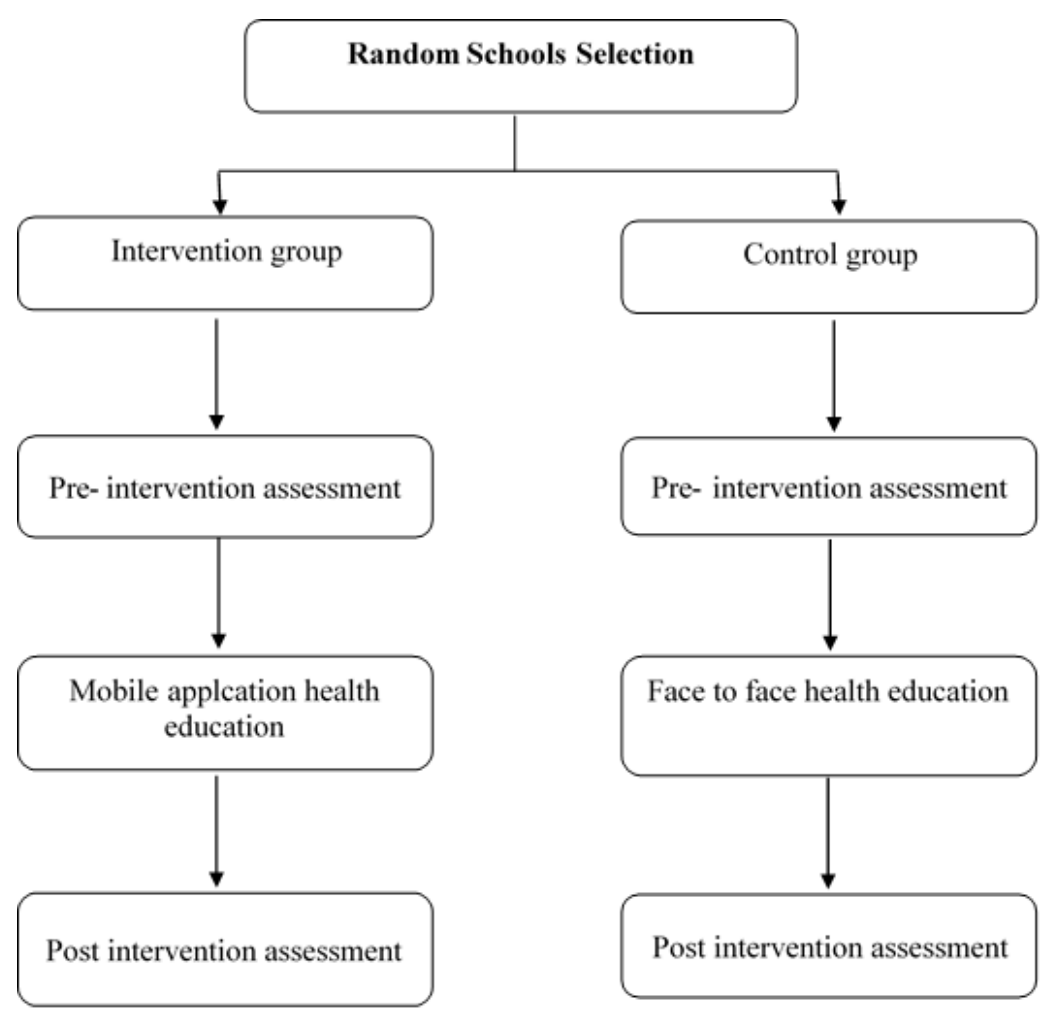

Figure 1

Research Design. 

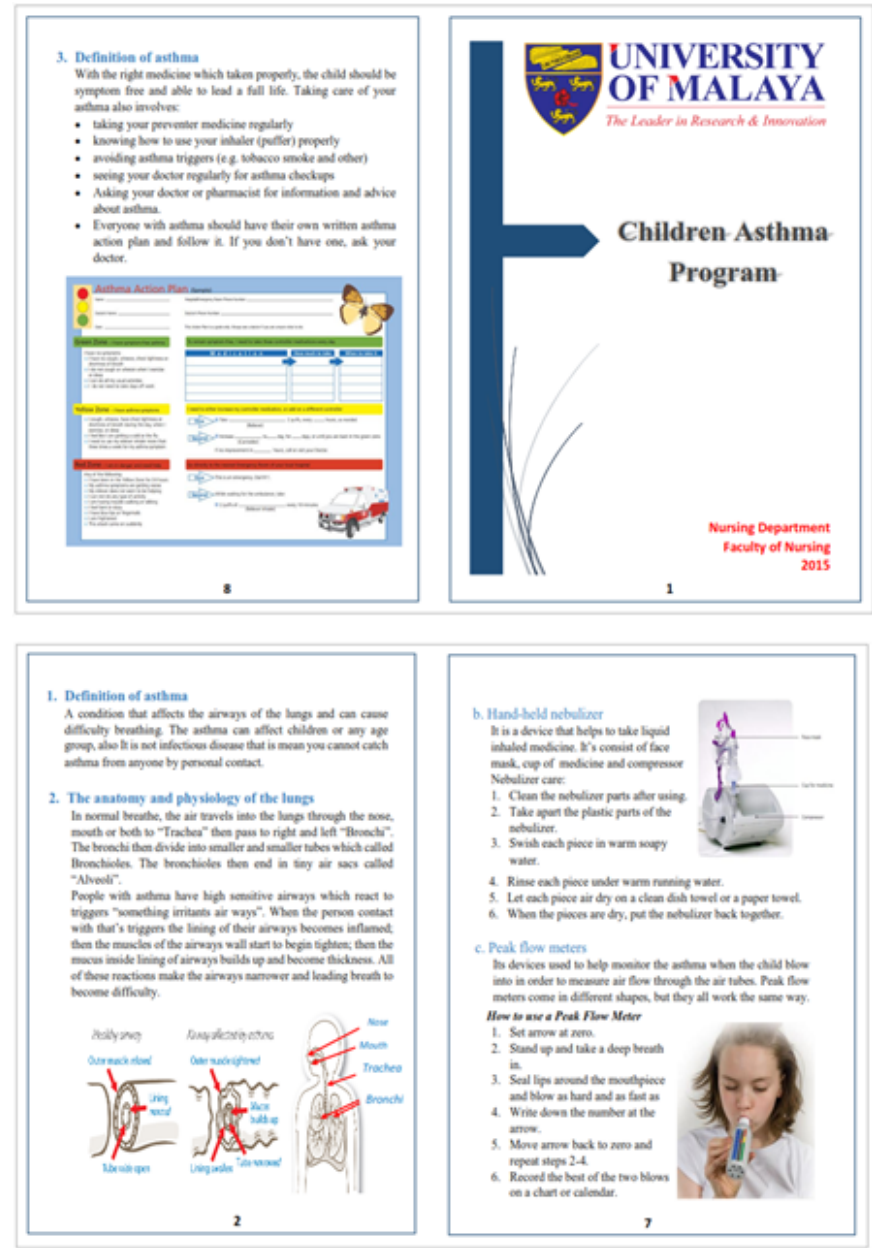

Figure 2

Children asthma hand workbook developed by research team

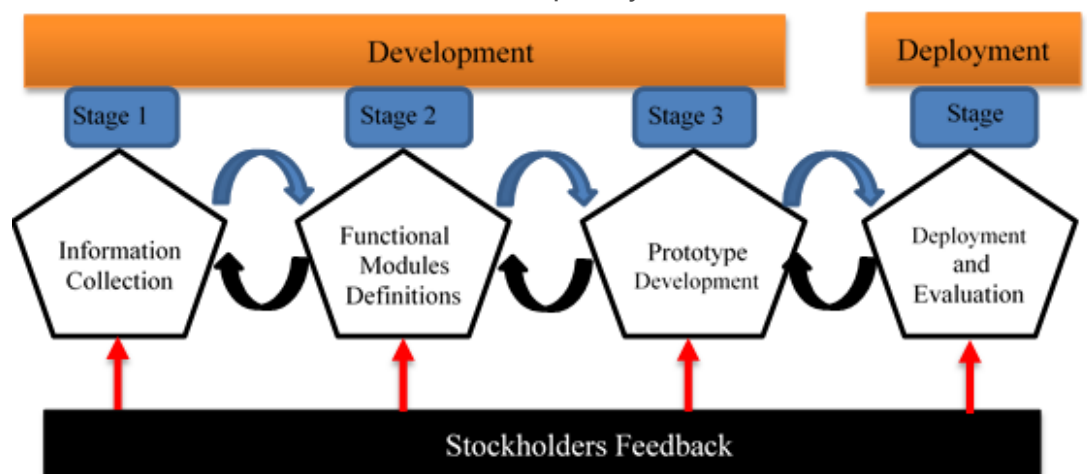

Figure 3

Design Process of MemahamiAsma ${ }^{\circledR}$ App 


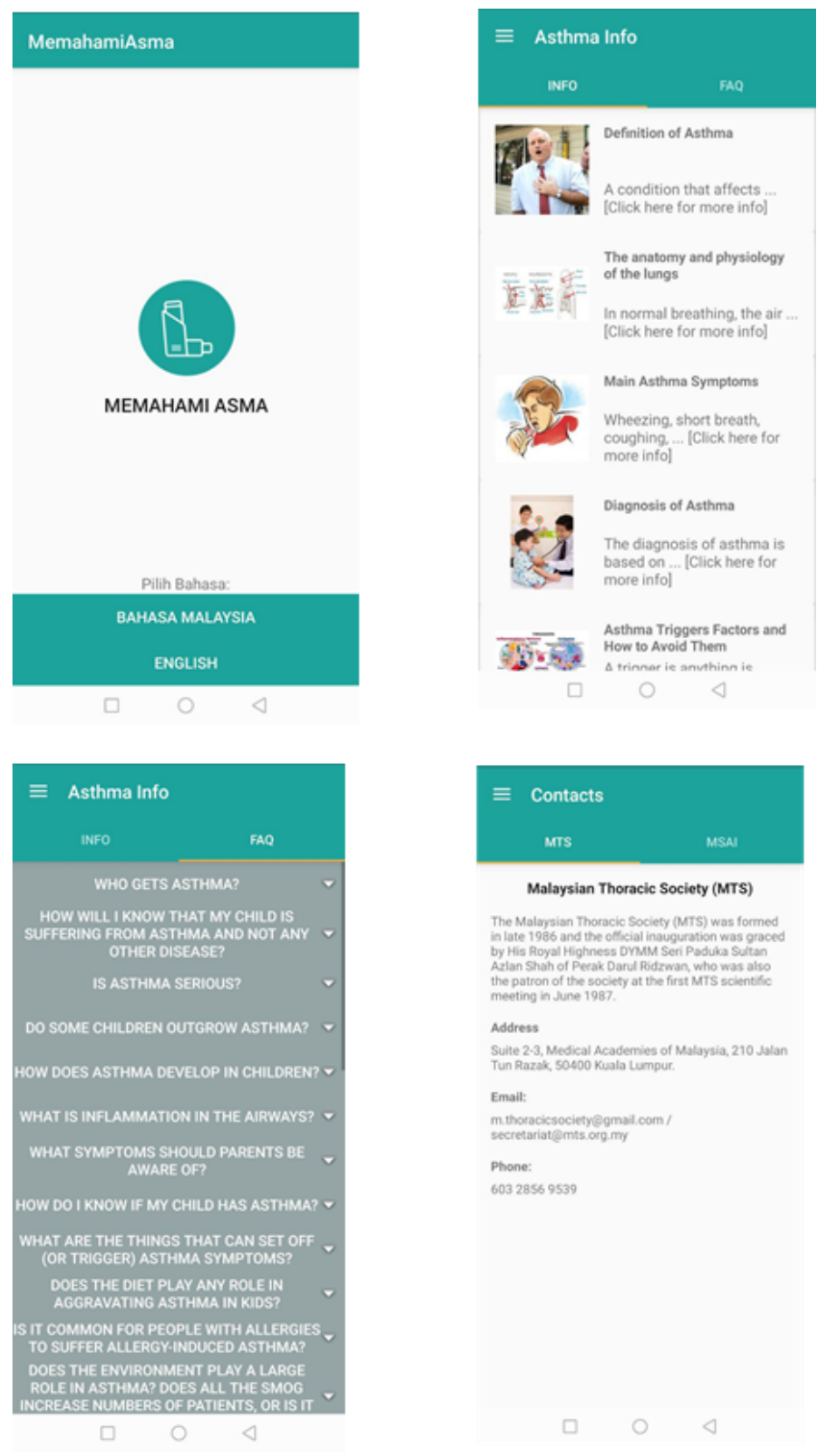

Figure 4

Screen shoot for mobile asthma app called: MemahamiAsma ${ }^{\circledR}$ 


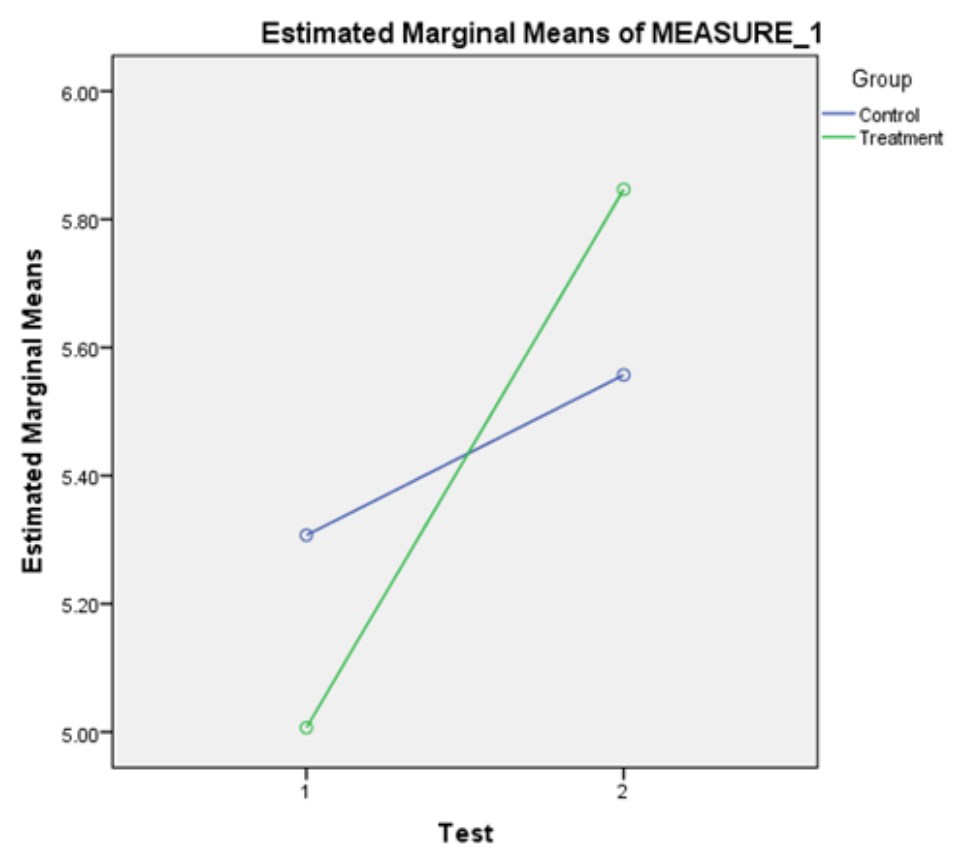

Figure 5

SPANOVA graph plot pre-intervention and post-intervention in control and experimental groups 